\title{
DFT Study of Leuco-Indigo and Indigo as Active Material in Dye-Sensitized Solar Cell
}

\author{
Mirella Fonda Maahury, ${ }^{1,}$, Yusthinus T. Male ${ }^{1}$, Muhamad A. Martoprawiro² \\ ${ }^{1}$ Chemistry Department, Faculty of Mathematics and Natural Science, Pattimura University, Ambon, Indonesia \\ ${ }^{2}$ Chemistry Department, Faculty of Mathematics and Natural Science, Institut Teknologi Bandung, \\ Bandung, Indonesia
}

*Corresponding author email: mirella.maahury@fmipa.unpatti.ac.id

Received October 16, 2019; Accepted May 22, 2020; Available online July 27, 2020

\begin{abstract}
Computational study of natural indigo has been carried out to get the optimized structure and electronic properties of two indigo at different $\mathrm{pH}$. It has been found that indigo has the potential to be applied as active material in the dye-sensitized solar cell. Computational calculations are performed using Density Functional Theory (DFT) with B3LYP functional and $6-31 \mathrm{G}(\mathrm{d}, \mathrm{p})$ for ground state geometry optimization and Time Dependent-Density Functional Theory (TD-DFT) for excited states single point calculation. All calculations are carried out in the gas phase. Geometry optimization results show that Indigo has a planar structure, whereas leuco-indigo structure is not planar. Leuco-indigo absorption wavelength is shorter than indigo. The density of HOMO and LUMO is spreading throughout the molecule. The density of electrons at LUMO extends to the anchoring group. Based on excitation energy, absorption wavelength, excitation composition, and HOMO-LUMO density, it can be concluded that indigo has the potential to be applied in dye-sensitized solar cell (DSSC).
\end{abstract}

Keywords: Indigo, leuco-indigo, DSSC, HOMO-LUMO, DFT, Anchoring group.

\section{INTRODUCTION}

Indigo dye is an organic compound with a distinctive blue color. Historically, indigo was a natural dye extracted from the leaves of an indigo plant (Indigofera tinctoria L.), and this process was important economically because blue dyes were once rare in the past. Its blue color is distinctly attractive and impressive fork those who touch. No wonder, it was named "the King of Dyes" (Teanglum, Teanglum, \& Saithong, 2012).

Indigo has different structures, depending on the $\mathrm{pH}$ of the solution. At acidic $\mathrm{pH}$, leuco-indigo is formed whereas, at basic $\mathrm{pH}$, indigo does not change. Indigo gives blue to red color because it has a resonance structure. Instead, leuco-indigo has no color, but it is resonant in its structure. Leuco-indigo is a reduced product from indigo. The structure of leucoindigo and indigo are shown in Figure 1.

Indigo extract shows potential as a good antioxidant, which is due to its resonance structure, which allows electron delocalization. The delocalized electron has a narrower energy gap, which facilitates easy electron excitation, which subsequently maintains the supply of electrons to prevent oxidation. Indigo from plants has been investigated for antioxidant activity. Farias-silva et al. (2007) have investigated the antioxidant activity of indigo from Aerial part Indigofera truxillensis and obtained indigo from that plant to give an antioxidant mechanism for gastroprotective effect (Farias-Silva et al., 2007).
Indigo and leuco-indigo can be applied as active material in the dye-sensitized solar cell. Research has been done to study the potential of indigo as active materials in the organic solar cell. For example, Basuki (2018) mix curcumin and indigo $(0.23 \mathrm{~m} / 0.23 \mathrm{M})$ as a sensitizer in Dye-sensitized solar cell (DSSC) and give conversion efficiency about $0.038 \%$ (Basuki, 2018). Indigo and leuco-indigo, as active material in a dyesensitized solar cell, can be investigated using a computational method.

The development of dyes compounds can be done both experimentally and in a modeling approach. Experimental results will provide accurate results but require a relatively greater time and cost when compared to modeling using computational chemistry methods. With modeling can be obtained estimates of the nature of the compound of the model with low cost and short time, but to be able to provide accurate data will depend very much on the theoretical approach taken (Cramer, 2004).

Computational research has been carried out on indigo and its derivatives compound as active material in dye-sensitized solar cells. Cervantes-navaro et al. (2013) have been studied indigo and its derivatives as photosensitizers in dye-sensitized solar cells computationally using B3LYP/6-31G(d,p) for the ground state and TD-DFT B3LYP/6-31G(d,p) for excited state in gas phase (Cervantes-Navarro \& Glossman-Mitnik, 2013). 


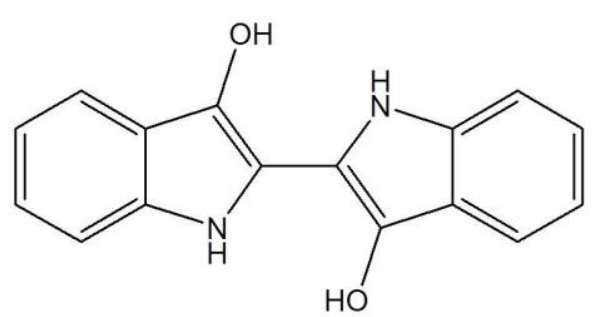

(a)

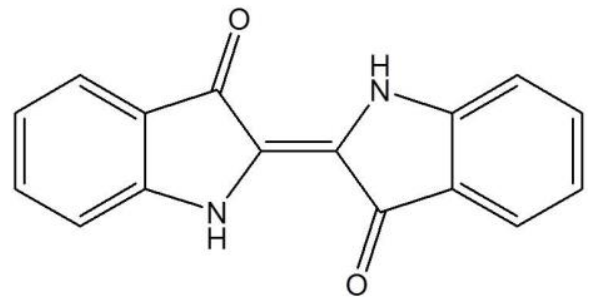

(b)

Figure 1 Structures leuco-indigo (a) and indigo (b).

There are many researchers who used DFT B3LYP/6-31G(d,p) as the model theory for calculation natural dyes as a photosensitizer in DSSC. El Alamy et al. (2017) have been used DFT and TDDFT with the B3LYP/6-31G(d,p) to calculate new compounds based on phenylenevinylene and thiophene/furan which determined and investigated geometries and optoelectronic properties (El alamy, Bourass, Amine, Hamidi, \& Bouachrine, 2017). Irfan et al. (2018) have been investigated stable structure, electro-optical, charge transport and nonlinear optical properties of (4Z)-4-Benzylidene-2-(4-methylphenyl)-1,3-oxazol$5(4 \mathrm{H})$-one and its derivatives using DFT and TDDFT with the B3LYP/6-31G** (Irfan, Al-Sehemi, Chaudhry, \& Muhammad, 2018). Both of these calculation gets reasonable structure and values.

Cervantes-navaro et al. (2013) have investigated indigo and four derivatives of indigo. The result from this calculation, five molecules can work in DSSC with $\mathrm{TiO}_{2}$ than $\mathrm{ZnO}$. Based on oscillator strength data to calculate light-harvesting efficiency (LHE), indigo with four Bromium atoms (tetrabromoindigo) has the highest LHE.

The computational calculation earlier is only for indigo. There is no computational study about indigo and leuco-indigo, as material active in dye-sensitized solar cell, so this research about Computational Study of indigo and leuco-indigo as Active Material in DyeSensitized Solar Cell. The computational study was performed to get optimized structure and electronic properties of indigo and leuco-indigo, and also to predict which compound has good potential as active material in dye-sensitized solar cells. The prediction resulted from the comparison of several properties that contribute to the quality of dye for solar cell, such as absorption wavelength, energy transition, the density of highest occupied molecular orbital (HOMO) and lowest unoccupied molecular orbital (LUMO).

\section{EXPERIMENTAL SECTION}

Computational calculation using DFT (Density Functional Theory) for geometry optimization and TDDFT (Time-dependent Density Functional Theory) for excited state. Both of the calculation using functional B3LYP and basis set 6-31G(d,p). Geometry optimization has done for two compounds, indigo and leuco-indigo. The calculation for geometry optimization and excited state is in the gas phase. The output data of optimized geometry is a threedimensional structure, infrared spectrum, and HOMO-LUMO energy. The output from excitation state calculation data is excited energy, exciting composition, absorption wavelength, and HOMOLUMO density. As we know, the accurate properties of a molecule can be predicted if the structure of a molecule is optimized to obtain a stable structure.

\section{RESULTS AND DISCUSSION \\ Optimized structure}

Indigo naturally be in two structures depend on $\mathrm{pH}$. Indigo has a backbone in which there is two phenyl rings are directly connected by heptadiene chain. The differentiator of these two indigo is a functional bond to $C 7$ and $C 11$. Leuco-indigo has two hydroxyls $(-\mathrm{OH})$, whereas indigo contains two carbonyls $(-\mathrm{C}=\mathrm{O})$. Leuco-indigo has no planar structure. The non-planar structure is caused by a single bond which connected to two. Indigo has a planar structure because there is a double bond connected to the two of benzene. The optimized structure of leuco-indigo and indigo are shown in Figure 2.

The difference bond length and bond angles from leuco-indigo and indigo are causing by the different functional groups of both them. Left part and right part are identical because parameter such as bond length, bond angle, and dihedral from both of part are same. Bond length $R_{7,8}$ and $R_{10,11}$ leuco-indigo is shorter than indigo about $0.11 \AA$. Bond length $R_{8,10}$ for leuco-indigo is longer than indigo because bond for leuco-indigo is single bond whereas double bond for indigo. Bond angle $A_{7,8,10}$ for leuco-indigo is greater than indigo about $4.3^{\circ}$. The optimized structure parameter for leuco-indigo and indigo are shown in Table 1.

The dihedral of both molecules is different. The dihedral of indigo is $0^{\circ}$, so that we can tell the structure for indigo is planar. The dihedral for leuco-indigo is about $\pm 0.2^{\circ}$. This number indicates that the structure of leuco-indigo is not planar. Indigo has a planar stable structure. It can be caused by a double $O$ (ketone), which bonds to $C 7$ and $C 11$ atom. This structure has one pi bonding and one sigma bonding. The rotation of the $s p^{2}$ structure has difficulty in rotation and bending. On the other side, leuco-indigo forms a non-planar structure, because it has a single binding hydroxy group. Single bonds are very easy to rotation and bending. The planarity of the molecule 
can make molecule interaction with other molecules easily. Effect steric of the planar structure is less than non-planar molecule.

\section{Atomic Charge}

Atomic charge of the molecule can indicate the reactivity of the molecule. The reactivity refers to how the molecule can interact with another molecule. Atomic charge of leuco-indigo and indigo are shown in Table 2. The atomic charge for both molecules from left and right side have the same value. This shows that two parts, left and right, are identical. The atomic charge for indigo and leuco-indigo has a different number on atom $\mathrm{C} 7$ and $\mathrm{C} 11$. The number of the atomic charge of the two $\mathrm{C}$ atoms in indigo is greater than that in leuco-indigo. This is caused by differences in functional groups that are bound to this $C$ atom. For this reason, it can be said that the presence of a double $O$ group has a stronger electron withdrawal effect than the hydroxy group. The number of atom C7 and $C 11$ is different because it shows the order in the molecular molecules to arrange the z-matrix. The atoms C7 and C11 are Carbon atoms and have the same atomic charge value because the left and the right sides are identical to each other.

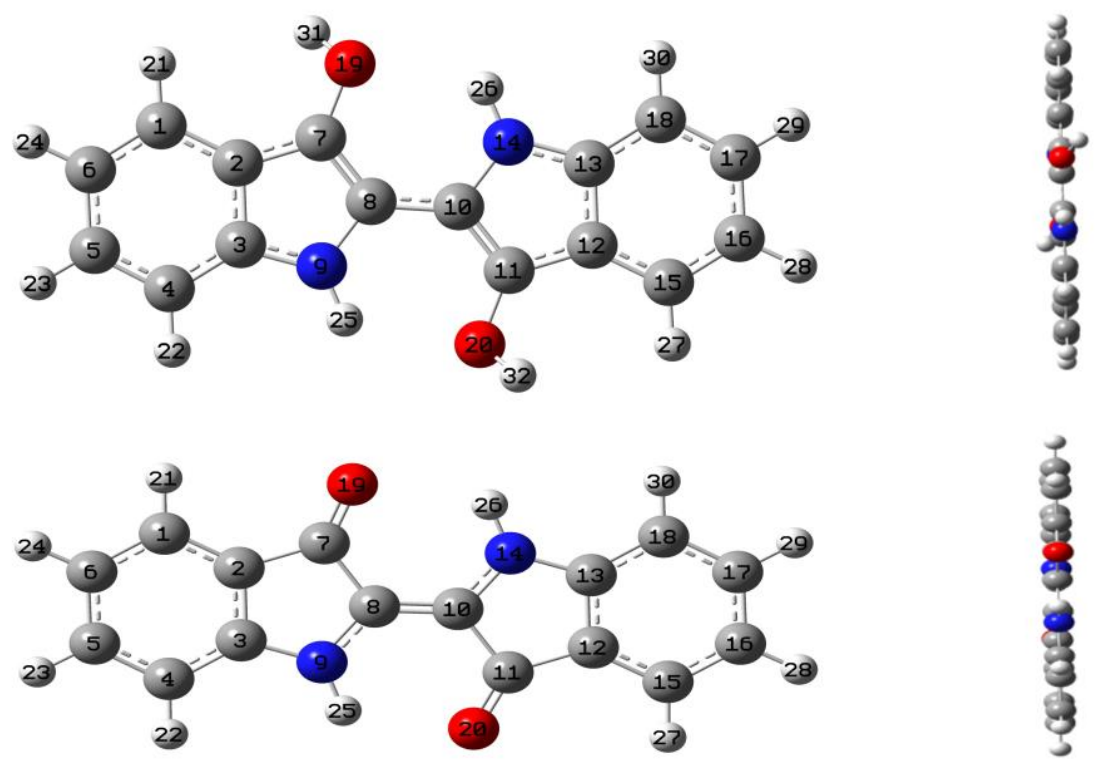

(a)

(b)

Figure 2. Optimized structure of leuco-indigo (a) and indigo (b).

Table 1. Optimized structure of parameter leuco-indigo and indigo

\begin{tabular}{|c|c|c|c|c|c|c|c|c|c|c|c|c|c|}
\hline \multirow{3}{*}{$\begin{array}{c}\text { Molec } \\
\text { ule }\end{array}$} & \multicolumn{6}{|c|}{ Left part } & \multicolumn{6}{|c|}{ Right Part } & \multirow{3}{*}{$\begin{array}{c}\begin{array}{c}\text { Middle } \\
\text { part }\end{array} \\
\begin{array}{c}\text { Bond } \\
\text { length } \\
(\AA)\end{array} \\
\mathrm{R}_{8,10}\end{array}$} \\
\hline & \multicolumn{3}{|c|}{$\begin{array}{c}\text { Bond length } \\
(\AA)\end{array}$} & \multicolumn{2}{|c|}{$\begin{array}{c}\text { Bond angle } \\
\left({ }^{\circ}\right)\end{array}$} & \multirow{2}{*}{$\begin{array}{c}\begin{array}{c}\text { Dihedr } \\
\text { al } \\
\left({ }^{\circ}\right)\end{array} \\
D_{2,7,8,9}\end{array}$} & \multicolumn{3}{|c|}{$\begin{array}{c}\text { Bond length } \\
(\AA)\end{array}$} & \multicolumn{2}{|c|}{$\begin{array}{c}\text { Bond angle } \\
\left({ }^{\circ}\right)\end{array}$} & \multirow{2}{*}{\begin{tabular}{|c|}
$\begin{array}{c}\text { dihedr } \\
\text { al } \\
\left({ }^{\circ}\right)\end{array}$ \\
$D_{14,10,11,12}$
\end{tabular}} & \\
\hline & $\mathrm{R}_{2,3}$ & $\mathrm{R}_{7,8}$ & $\mathrm{R}_{2,7}$ & $<2,7,8$ & $<_{7,8,10}$ & & $R_{12,13}$ & $R_{10,11}$ & $R_{12,11}$ & $<10,11,12$ & $<_{8,10,11}$ & & \\
\hline $\begin{array}{l}\text { leuco- } \\
\text { indigo }\end{array}$ & 1.43 & 1.38 & 1.43 & 108.46 & 130.01 & -0.1996 & 1.43 & 1.38 & 1.43 & 108.46 & 130.01 & 0.198 & 1.44 \\
\hline Indigo & 1.42 & 1.49 & 1.47 & 104.27 & 125.69 & 0.0 & 1.42 & 1.49 & 1.47 & 104.27 & 125.69 & 0.0 & 1.36 \\
\hline
\end{tabular}

Table 2. Atomic charge of leuco-indigo and indigo

\begin{tabular}{|l|l|l|l|l|l|l|l|l|l|l|}
\hline \multirow{2}{*}{ Molecule } & \multicolumn{10}{|c|}{ Atomic Charge } \\
\cline { 2 - 11 } & $\mathrm{C} 2$ & $\mathrm{C} 3$ & $\mathrm{C} 7$ & $\mathrm{C} 8$ & $\mathrm{~N} 9$ & $\mathrm{C} 10$ & $\mathrm{C} 11$ & $\mathrm{C} 12$ & $\mathrm{C} 13$ & N14 \\
\hline $\begin{array}{l}\text { Leuco- } \\
\text { indigo }\end{array}$ & 0.101 & 0.315 & 0.152 & 0.319 & -0.724 & 0.319 & 0.152 & 0.101 & 0.315 & -0.724 \\
\hline Indigo & 0.029 & 0.339 & 0.358 & 0.265 & -0.723 & 0.265 & 0.358 & 0.029 & 0.339 & -0.723 \\
\hline
\end{tabular}




\section{Transition energy and transition percentage}

The transition of an electron from HOMO to LUMO can occur due to three main ways: i.e., the absorption of photons, electron shooting to the molecule, and the high-energy collision between molecules. In the context of DSSC, electron excitations are expected to occur by photons from sunlight, especially in the visible region. Transition energy can be calculated from the difference between $\mathrm{HOMO}$ and LUMO. The transition energy of indigo from our calculation is lower than the transition energy of leuco-indigo. Electron in indigo needs smaller energy to transfer to an excited state. The transition percentage shows how much percentage of the type of vertical excitation takes place in maximum absorption wavelength $(\lambda)$. Leuco-indigo has a lower absorption wavelength than indigos. Leuco-indigo, in its absorption wavelength, only has single, HOMO-LUMO transition. On the other hand, Indigo in its absorption wavelength has HOMO to LUMO transition (dominant), but reverse excitation happens, too.

The absorption wavelength of indigo from the calculation is in the range wavelength from experiments. Absorption wavelength from the experiment be in the visible range of about 500-700 $\mathrm{nm}$ (Wahyuningsih et al., 2017), the absorption wavelength from the calculation is $534.72 \mathrm{~nm}$. This result shows that the theory and basis set for this calculation can provide an accurate number for this molecule.

The important thing about the dye-sensitized solar cell is efficiency conversion, which given by active material in the device to obtain current. The light-harvesting efficiency (LHE) is the way to confirm how much efficiency conversion from the active material which can be calculated (Nalwa, 2001). The formula is given in equation (1), with $f$ is oscillator strength. Higher oscillator strength from computational calculation shows higher absorption constant $A$. The number of LHE can be seen in Table 3.

$$
\text { LHE }=1-10^{-f}
$$

The LHE of leuco-indigo is higher than the LHE of indigo. Transition data of leuco-indigo reinforce this number. Leuco-indigo only has one transition; there is transition $\mathrm{HOMO}$ to LUMO. In another side, indigo has two possible transitions that occur; there are excitation processes from $\mathrm{HOMO}$ to LUMO and reverse transition from LUMO to HOMO.

\section{HOMO-LUMO display}

Electron density of HOMO and LUMO also determine the electronic properties of molecules important for application in DSSC. The dye molecules that are good for application in DSSC should have an overlapping density of HOMO and LUMO. This overlapping density will facilitate vertical excitation. Vertical excitation happens when photo-excitation of an electron from HOMO to LUMO occurs without moving to another area in the molecule. The lower transition energy means easier electron excitation.

If the density of HOMO-LUMO spreads in the entire molecule and also overlaps as explained above, the transfer from HOMO to LUMO can take place easily. However, this overlap also makes it easier for electrons to drop back from LUMO to HOMO that is not expected in dye molecules for solar cell. The preventing way for this situation, the density of LUMO, should spread to the anchoring group, after the excitation process from HOMO to LUMO, to subsequently be transferred to the semiconductor in DSSC.

The display of the highest occupied molecular orbital (HOMO) and lowest unoccupied molecular orbital (LUMO) are shown in Figure 3. The display of $\mathrm{HOMO}$ and LUMO shows how the distribution of molecular orbital for each molecule. HOMO and LUMO of leuco-indigo spread in the entire backbone of the molecule. However, the LUMO density of leucoindigo is not overlapping with $\mathrm{HOMO}$, which causes difficulty in excitation from HOMO to LUMO. HOMO and LUMO of indigo spread in the entire backbone of the molecule and overlapped. This overlap of $\mathrm{HOMO}$ and LUMO explains why indigo has two types of transition in the visible wavelength, i.e., excitation and de-excitation.

The LUMO density supports the facilitating transfer of electrons to the semiconductor. The LUMO density must extend to a functional group on the surface of the molecules. The functional group for leuco-indigo is hydroxy, and the functional group for indigo is $\mathrm{C}=\mathrm{O}$ double bond or ketone. The density of LUMO in the functional group makes the molecule can transfer electrons to the semiconductor and continuing it to the circuit in the device. In Figure 3, the density of LUMO in leuco-indigo is less dense than the LUMO in indigo. The less-dense means, the excitation can happen, but the number of electrons transfer to a semiconductor is less. The more dense LUMO for indigo means, the excitation can happen, and the number of electron transfer from the dye to a semiconductor is more facilitated.

Table 3. Excitation properties

\begin{tabular}{lccccc}
\hline Molecule & $\lambda(\mathrm{nm})$ & $\begin{array}{c}\text { Transition energy } \\
(\mathrm{eV})\end{array}$ & $f$ & Transition percentage & $\mathrm{LHE}$ \\
\hline Leuco-indigo & 349.89 & 3.5435 & 0.7854 & $\mathrm{HOMO} \rightarrow \mathrm{LUMO}(100 \%)$ & 0.836 \\
\hline Indigo & 534.72 & 2.3187 & 0.2736 & $\mathrm{HOMO} \rightarrow \operatorname{LUMO}(97.40 \%)$ & 0.467 \\
\hline \multicolumn{7}{c}{} \\
\hline
\end{tabular}




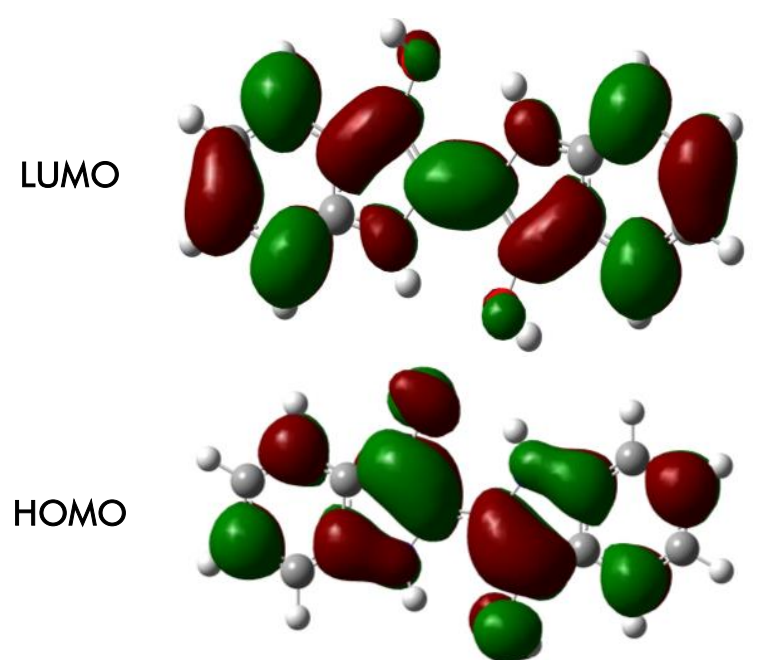

(a)
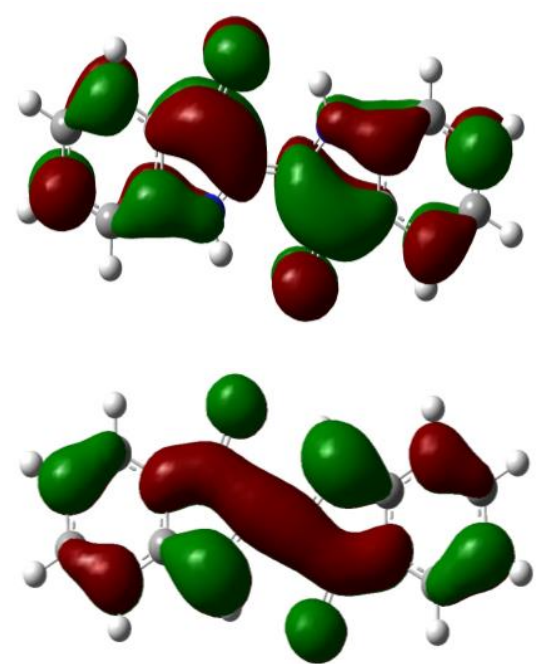

(b)

Figure 3. The display of HOMO and LUMO of leuco-indigo (a), and indigo (b)

\section{Orbital population}

Analysis of orbital population can explain which orbital contribute to the spreading of HOMO-LUMO quantitatively. The percentage orbital population of each atom in molecule leuco-indigo and indigo is given in Table 4. The percentage orbital population of Leuco-indigo shows that orbital $s$ and $p$ give a contribution to the spreading of HOMO-LUMO in the molecule. The percentage orbital population of indigo shows that only orbital $p$ give a contribution to the spreading of HOMO-LUMO in the molecule.

Based on Table 4, the percentage of orbital population leuco-indigo in the left part and right part are the same. This trend is happening in indigo too. This trend shows that the left part and right part of indigo are identical, not only based on the parameter of structure but also based on the electronic parameters, such as percentage orbital population. The contributions from s orbitals are only found in part of the molecule, which bound to functional groups. The part of the molecule which only containing carbon (benzene) atoms, the contribution is only given by $\mathrm{p}$ orbitals.

\section{Infrared spectrum}

The Infrared spectrum of leuco-indigo and indigo are different (Figure 4). Leuco-indigo has a peak at $1500 \mathrm{~cm}^{-1}$, refers to stretch C-O for alcohol $(\sim 3300$ $\mathrm{cm}^{-1}$ ). Leuco-indigo shows a peak for $\mathrm{C}=\mathrm{C}$ aromatic about $1400 \mathrm{~cm}^{-1}$ and $\mathrm{C}-\mathrm{H}$ benzene about $300 \mathrm{~cm}^{-1}$. Indigo has a sharp peak at about $1600 \mathrm{~cm}^{-1}$, refers to stretch $\mathrm{C}=\mathrm{O}$ (carbonyl). Indigo shows a peak for $\mathrm{C}=\mathrm{C}$ aromatic about $1400 \mathrm{~cm}^{-1}$, but for $\mathrm{C}-\mathrm{H}$ benzene, it does not appear.

The infrared spectrum is used to show the fingerprints of each molecule that are carried out for the calculation as well as to test the calculation itself whether it shows the functional groups of the molecules being counted. Effectiveness is supported from UV-vis absorption data obtained where indigo has absorption in the visible light region which is the sunlight region for DSSC.

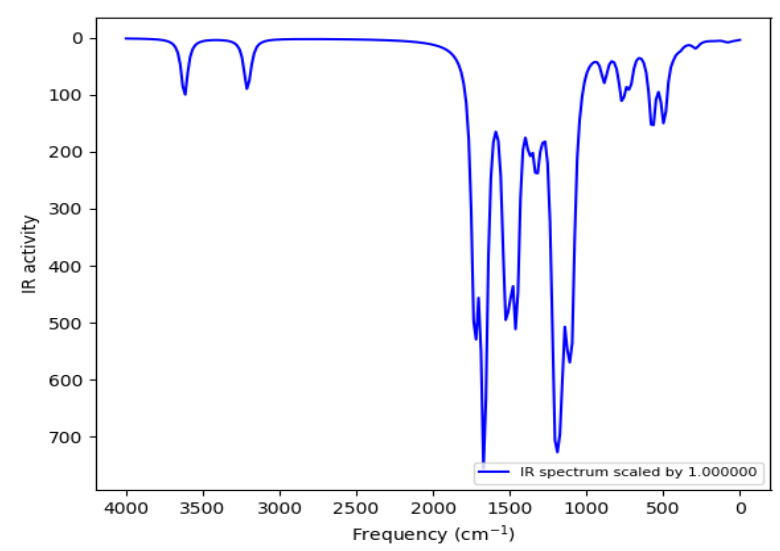

(b)

(a)

Figure 4. The infrared spectrum of leuco-indigo (a), and indigo (b) 
Table 4. Percentage of the orbital population of leuco-indigo and indigo

\begin{tabular}{|c|c|c|c|c|c|c|c|c|c|c|c|c|c|c|c|c|c|c|c|c|c|}
\hline \multirow{2}{*}{ Molecule } & & \multicolumn{2}{|c|}{$1 \mathrm{C}$} & \multicolumn{2}{|c|}{$2 C$} & \multicolumn{2}{|c|}{$3 C$} & \multicolumn{2}{|c|}{$4 C$} & \multicolumn{2}{|c|}{$5 C$} & \multicolumn{2}{|c|}{$6 C$} & \multicolumn{2}{|c|}{$7 C$} & \multicolumn{2}{|c|}{$8 C$} & \multicolumn{2}{|c|}{$9 \mathrm{C}$} & \multicolumn{2}{|c|}{$10 C$} \\
\hline & & $S$ & $p$ & $S$ & $p$ & $s$ & $p$ & $s$ & $P$ & $s$ & $p$ & $s$ & $p$ & $S$ & $p$ & $S$ & $p$ & $s$ & $p$ & $s$ & $p$ \\
\hline \multirow{12}{*}{$\begin{array}{l}\text { Leuco- } \\
\text { indigo }\end{array}$} & $\mathrm{NHOMO}$ & 0.00 & 5.71 & 0.02 & 1.45 & 0.01 & 0.22 & 0.00 & 7.45 & 0.00 & 1.00 & 0.00 & 5.60 & 0.02 & 6.79 & 0.03 & 2.63 & 0.02 & 18.25 & 0.03 & 2.63 \\
\hline & HOMO & 0.01 & 4.71 & 0.02 & 0.59 & 0.01 & 4.96 & 0.00 & 0.31 & 0.00 & 6.33 & 0.00 & 0.11 & 0.07 & 14.53 & 0.39 & 10.23 & 0.00 & 1.11 & 0.39 & 10.23 \\
\hline & LUMO & 0.00 & 10.49 & 0.01 & 2.09 & 0.00 & 0.35 & 0.00 & 7.87 & 0.00 & 7.52 & 0.00 & 1.09 & 0.00 & 8.20 & 0.02 & 7.80 & 0.06 & 3.74 & 0.02 & 7.80 \\
\hline & NLUMO & 0.00 & 14.57 & 0.01 & 3.97 & 0.00 & 4.67 & 0.00 & 14.77 & 0.00 & 4.69 & 0.00 & 3.87 & 0.01 & 0.06 & 0.01 & 3.19 & 0.00 & 0.11 & 0.01 & 3.18 \\
\hline & & \multicolumn{2}{|c|}{$11 C$} & \multicolumn{2}{|c|}{$12 \mathrm{C}$} & \multicolumn{2}{|c|}{$13 C$} & \multicolumn{2}{|c|}{$14 \mathrm{C}$} & \multicolumn{2}{|c|}{$15 \mathrm{C}$} & \multicolumn{2}{|c|}{$16 C$} & \multicolumn{2}{|c|}{$17 C$} & \multicolumn{2}{|c|}{$18 \mathrm{C}$} & \multicolumn{2}{|c|}{190} & \multicolumn{2}{|c|}{200} \\
\hline & & $S$ & $p$ & $S$ & $p$ & $s$ & $p$ & $s$ & $P$ & $s$ & $p$ & $s$ & $p$ & $S$ & $p$ & $S$ & $p$ & $s$ & $p$ & $s$ & $p$ \\
\hline & $\mathrm{NHOMO}$ & 0.02 & 6.79 & 0.03 & 1.46 & 0.01 & 0.22 & 0.02 & 18.26 & 0.00 & 5.71 & 0.00 & 5.61 & 0.00 & 1.00 & 0.00 & 0.75 & 0.14 & 4.01 & 0.13 & 4.02 \\
\hline & HOMO & 0.07 & 14.52 & 0.02 & 0.59 & 0.01 & 4.96 & 0.00 & 1.11 & 0.01 & 4.71 & 0.00 & 0.11 & 0.00 & 6.33 & 0.00 & 0.31 & 0.33 & 6.30 & 0.33 & 6.30 \\
\hline & LUMO & 0.00 & 8.20 & 0.01 & 2.09 & 0.00 & 0.35 & 0.06 & 3.74 & 0.00 & 10.50 & 0.00 & 1.09 & 0.00 & 7.52 & 0.00 & 7.88 & 0.15 & 1.27 & 0.03 & 0.04 \\
\hline & NLUMO & 0.01 & 0.06 & 0.01 & 3.97 & 0.00 & 4.68 & 0.00 & 0.11 & 0.00 & 14.58 & 0.00 & 3.88 & 0.00 & 3.54 & 0.00 & 14.77 & 0.13 & 1.06 & 0.03 & 0.04 \\
\hline & & \multicolumn{2}{|c|}{$1 \mathrm{C}$} & \multicolumn{2}{|c|}{$2 C$} & \multicolumn{2}{|c|}{$3 C$} & \multicolumn{2}{|c|}{$4 C$} & & C & & C & & C & & C & & & & $C$ \\
\hline & & $S$ & $p$ & $S$ & $p$ & $s$ & $p$ & $s$ & $P$ & $s$ & $p$ & $s$ & $p$ & $S$ & $p$ & $S$ & $p$ & $s$ & $p$ & $s$ & $P$ \\
\hline Indigo & NHOMO & 0.00 & 0.73 & 0.00 & 7.72 & 0.00 & 8.59 & 0.00 & 3.73 & 0.00 & 3.07 & 0.00 & 11.50 & 0.00 & 0.02 & 0.00 & 2.72 & 0.00 & 10.87 & 0.00 & 2.01 \\
\hline & HOMO & 0.00 & 1.38 & 0.00 & 3.28 & 0.00 & 0.17 & 0.00 & 4.48 & 0.00 & 0.07 & 0.00 & 4.87 & 0.00 & 1.42 & 0.00 & 7.44 & 0.00 & 20.56 & 0.00 & 7.64 \\
\hline & LUMO & 0.00 & 3.67 & 0.00 & 1.56 & 0.00 & 3.79 & 0.00 & 0.03 & 0.00 & 4.74 & 0.00 & 0.29 & 0.00 & 9.11 & 0.00 & 10.72 & 0.00 & 1.52 & 0.00 & 10.58 \\
\hline & NLUMO & 0.00 & 11.60 & 0.00 & 4.49 & 0.00 & 0.40 & 0.00 & 8.40 & 0.00 & 9.72 & 0.00 & 0.31 & 0.00 & 6.09 & 0.00 & 3.05 & 0.00 & 1.59 & 0.00 & 3.31 \\
\hline & & & IC & & & & & & $4 \mathrm{C}$ & & 5 & & $C$ & & C & & C & & & & 0 \\
\hline & & $S$ & $p$ & $S$ & $p$ & $s$ & $p$ & $s$ & $P$ & $s$ & $p$ & $s$ & $p$ & $S$ & $p$ & $s$ & $p$ & $s$ & $p$ & $s$ & $p$ \\
\hline & NHOMO & 0.00 & 0.03 & 0.00 & 7.51 & 0.00 & 8.17 & 0.00 & 12.25 & 0.00 & 0.78 & 0.00 & 11.39 & 0.00 & 2.74 & 0.00 & 4.02 & 0.00 & 0.98 & 0.00 & 1.20 \\
\hline & HOMO & 0.00 & 1.42 & 0.00 & 2.87 & 0.00 & 0.10 & 0.00 & 20.00 & 0.00 & 1.29 & 0.00 & 4.29 & 0.00 & 0.10 & 0.00 & 4.04 & 0.00 & 8.55 & 0.00 & 7.19 \\
\hline & LUMO & 0.00 & 9.47 & 0.00 & 1.59 & 0.00 & 3.84 & 0.00 & 1.54 & 0.00 & 3.82 & 0.00 & 0.27 & 0.00 & 4.93 & 0.00 & 0.04 & 0.00 & 14.13 & 0.00 & 14.39 \\
\hline & NLUMO & 0.00 & 5.90 & 0.00 & 4.57 & 0.00 & 0.34 & 0.00 & 1.65 & 0.00 & 11.66 & 0.00 & 0.32 & 0.00 & 9.67 & 0.00 & 8.60 & 0.00 & 4.29 & 0.00 & 4.09 \\
\hline
\end{tabular}




\section{CONCLUSIONS}

Based on geometry optimization calculation using DFT, the optimized structure of leuco-indigo is nonplanar, while indigo is planar. The optimized structure, i.e. the structure with lowest energy (most stable structure) will be very close to their structure in nature. For example, we found that one of the molecules does not have planar structure that inhibit its possibility to delocalize its electrons. Based on data on electronic properties, indigo has better potency as the active material for application in DSSC. The better potency is due to the lower transition energy of indigo, the maximum wavelength in the visible range, and the density of HOMO and LUMO spreading to the entire molecule. Indigo also shows one important property of dye for solar cell, which is the electron density of LUMO extends to the anchoring group, which can be potentially connected directly to semiconductors in DSSC.

\section{REFERENCES}

Basuki. (2018). Kineria Pencampuran Pewarna Kunyit dan Indigofera dengan Molaritas Indigo/Kunyit 0,32M/0,23M sebagai Sensitizer Pada Dye Sensitized Solar Cells (DSSCC). Jurnal Reaktom, $01(02), 25-28$.

Cervantes-Navarro, F., \& Glossman-Mitnik, D. (2013). Density functional theory study of indigo and its derivatives as photosensitizers for dyesensitized solar cells. Journal of Photochemistry and Photobiology A: Chemistry, 255(February), 24-26. https://doi.org/10.1016/i.jphotochem. 2013.01 .011

Cramer. (2004). Essentials of Computational Chemistry.

El alamy, A., Bourass, M., Amine, A., Hamidi, M., \& Bouachrine, M. (2017). New organic dyes based on phenylenevinylene for solar cells: DFT and TD-DFT investigation. Karbala International
Journal of Modern Science, 3(2), 75-82. https://doi.org/10.1016/j.kijoms.2017.03.002

Farias-Silva, E., Cola, M., Calvo, T. R., Barbastefano, V., Ferreira, A. L., Michelatto, D. D. P., ... Souza Brito, A. R. M. (2007). Antioxidant activity of indigo and its preventive effect against ethanolinduced DNA damage in rat gastric mucosa. Planta Medica, 73(12), 1241-1246. https://doi.org/10.1055/s-2007-981613

Heo, B. G., Park, Y. J., Park, Y. S., Bae, J. H., Cho, J. Y., Park, K., ... Gorinstein, S. (2014). Anticancer and antioxidant effects of extracts from different parts of indigo plant. Industrial Crops and Products, 56, 9-16. https://doi.org/10.1016/ i.indcrop.2014.02.023

Irfan, A., Al-Sehemi, A. G., Chaudhry, A. R., \& Muhammad, S. (2018). The structural, electrooptical, charge transport and nonlinear optical properties of oxazole (4Z)-4-Benzylidene-2-(4methylphenyl)-1,3-oxazol-5(4H)-one derivative. Journal of King Saud University - Science, 30(1), 75-82.

https://doi.org/10.1016/i.jksus.2016.10.004

Nalwa, H. S. (2001). Handbook of Advanced Electronic and Photonic Materials and Devices. San Diego.

Teanglum, A., Teanglum, S., \& Saithong, A. (2012). Selection of indigo plant varieties and other plants that yield indigo dye. Procedia Engineering, 32, 184-190. https://doi.org/ 10.1016/i.proeng.2012.01.1255

Wahyuningsih, S., Ramelan, A. H., Wardani, D. K., Aini, F. N., Sari, P. L., Tamtama, B. P. N., \& Kristiawan, Y. R. (2017). Indigo Dye Derived from Indigofera Tinctoria as Natural Food Colorant. IOP Conference Series: Materials Science and Engineering, 193(1). https://doi.org/10.1088/1757899X/193/1/012048 